\title{
Medical Education
}

\section{Scientific Basis of Clinical Practice : The Birmingham Scheme}

\author{
R. E. SMITH
}

British Medical fournal, 1971, 4, 483-484

The idea for a course in clinical science after qualification has been dormant in many people's minds for some time. The Todd Report ${ }^{1}$ provoked Professor George Whitfield, who is in charge of postgraduate rraining in the Birmingham region, to take up the challenge which it expressed as follows:

"The years immediately following the intern year present the most urgent problems, both because of the number of trainees involved and because of the present disorganised state of training during those years. The present provision of separate and unrelated courses for specialist qualifications takes up a great deal of teachers' time and although important differences of interest, knowledge and skill will no doubt remain between specialties, at least for a long time to come, we think that if adequate training is to be made available for all doctors every effort must be made to find and emphasise the common features, which are often substantial, rather than the differences. The training of the future general practitioner, the consultant physician and the paediatric specialist, for example, need not differ greatly, particularly in the early stages. Courses common to a number of specialties could be arranged in clinical science, e.g. biochemistry and pulmonary physiology, and some further knowledge of clinical pharmacology is essential for all who prescribe drugs. Pathology plays an important part in postgraduate training in many branches of medicine; the facilities and staffing of many pathology laboratories must be improved if they are to make their proper contribution to professional training. There are many branches of clinical medicine in which a greater than average knowledge of community medicine is desirable; opportunities should be created for interested young clinicians in all specialties to get experience in epidemiological and statistical aspects of their own specialties, and a simple introduction, in courses provided by universities, to the principles of management and operational research. Consideration should be given to providing, in all large hospitals, formal instruction in this subject and in psychiatry, to be open to all first year trainees irrespective of the field in which their current appointment is held. Most doctors will at some time be expected to undertake some form of teaching; accordingly, in addition to the valuable part already played by scientific societies in providing young doctors with experience of public speaking and constructive criticism of their performance, the availability of short simple courses of basic teaching techniques would be useful to all doctors."

This is a long quotation but I obey the "all or none" law and give it in full. I was asked to be chairman of a committee to arrange such a course and what I say reflects its views. We aimed high, indeed too high. Lord Balfour when he presided over the Medical Research Council said that it was not possible to have applied science without pure science. While this may well be true for researchers, we discoveredas the physiologists had warned us-that it does not pay to be too pure. "His experience of teaching, certainly of teaching the medical student, had been that it was just that touch of

Warwickshire Postgraduate Medical Centre, Coventry

R. E. SMITH, M.B., F.R.C.P., Area Director of Postgraduate Medical Education applicability of what was thought as a matter of principle to what was going to take place ultimately in his medical career which held the student's attention without in any way debasing the coin of pure science." This was Joseph Barcroft's view.

Nevertheless, the first year's course survived. We included all that Todd mentioned and those who attended were enthusiastic listeners and questioners. At times we were disheartened by the small numbers; even so, this year we have more than doubled our numbers, which in the first year averaged 17. I told Lord Todd of our venture and the poor response, but he counselled me to be of good cheer for all such innovations had small beginnings.

\section{Participation of G.P.s}

We aimed at those in the first year after registration, but the course was open to all and perhaps the most gratifying feature was the relatively large numbers of general practitioners who attended and took an active part in discussions. Some junior staff attended but many were prevented by their clinical commitments or were already attending other courses concerned with higher qualifications. Several consultants said they would like to come but found it impossible to escape from other duties.

In the second year we therefore became less academic; and aimed at instruction which could be useful for any of the higher diplomas. We grouped and linked our subjects. In the first term the two lectures before tea were by physiologists, the one after on pharmacology and wherever possible closely integrated-for example, "Mechanism of ventricular ejection" and "Central nervous control of circulation" was followed by "Drugs acting on the heart." These subjects have been happily conjoined for over half a century. Fifty years ago I was taught by J. N. Langley, the professor of physiology at Cambridge who by pharmacological experiments with atropine, pilocarpine, and adrenaline delineated the autonomic nervous system into the parasympathetic and sympathetic nervous system. The approach is still the same: equipment may be more advanced but techniques for the study of transmission in various parts of the central nervous system do not seem to differ much from those Keith Lucas and E. D. Adrian used before the 1914-18 war.

One of those who started research under Langley was H. H. Dale, who with Otto Loewi showed that transmission of the impulse at the nerve ending was humoral. When the electrical impulse transmitted along the nerve fibre reached the synapse pharmacologically active agents such as acetylcholine and noradrenaline were discharged and these in turn activated the next excitable structure. He discovered that acetylcholine acted sometimes like muscarine, sometimes like nicotine. Sir Henry Dale died in 1968 at the venerable age of 93. In an obituary notice it is stated that the great practical use of his experiments has been the relief of symptoms and the prolongation of life-results which had surprised Dale. $^{3}$ 
The contributor, H.O.S., writes "An early application of these concepts was the clinical use of tubocurarine, which blocks the effects of acetylcholine at the neuromuscular junction. The muscle relaxants have since become indispensable aids to surgery. Another application has been the use of drugs which prevent the enzymatic destruction of acetylcholine, the anticholinesterases, to alleviate myasthenia gravis. One of the most important applications of the theory has been the use of drugs to control hypertension, including the use of ganglion-blockers which antagonise the effect of the transmitter substance acetylcholine at ganglia, adrenergic neuroneblocking drugs, such as guanethidine and bethanidine, which prevent the release of the transmitter substance noradrenaline at sympathetic nerve endings and drugs, such as methyldopa, which interfere with the synthesis of the sympathetic transmitter. Although these advances were brought about through the original contributions of many different research workers, they can all be regarded as natural extensions of Dale's ideas."3

All these are wonderful examples of the scientific basis of clinical practice.

If we are succeeding only slowly we have found new assets. We have established a valuable liaison with the teachers of the basic sciences. We have found that in their researches (and let us not forget John Ryle's dictum "Research fertilizes teaching") they can help the clinician in such ways as estimating angiotensin, renin, and aldosterone, or are willing to try to discover why lithium-now extensively employed in psychiatric treatment-occasionally causes side effects sometimes progressing to poisoning. We have proved that the Todd report was correct when it stated that all discliplines have common features: that the future consultant in medicine or paediatrics and the general practitioner want similar training. We are still experimenting constructively; we have added a small block of lectures on genetics and have substituted applied for pure psychology. We have included all branches of medical science and are getting support from those who plan special courses for individual higher qualifications such as the pathologists by consulting them to see how best we can co-operate.

"Every doctor should be free to choose those forms which best meet his own needs and suit his own circumstances." I hope those who wrote this in the Todd Report will approve of our efforts and be pleased that many refresh themselves with basic principles.

The members of the committee appointed by Professor A. G. W. Whitfield are Drs. R. E. Smith (Chairman); J. D. Blainey*; H. W. Everley Jones; M. G. FitzGerald; A. J. McCall; A. Paton; and K. Young. Details of the course can be obtained by writing to Dr. R. E. Smith, Warwickshire Postgraduate Medical Centre, Stoney Stanton Road, Coventry, CV1 4FG.

* Dr. J. D. Blainey resigned in 1971.

\section{References}

1 Royal Commission on Medical Education, Report, 1965-8, Cmnd. 3569. London, H.M.S.O., 1968.

2 Cambridge and its Contribution to Medicine, in Proceedings of the British Congress of the History of Medicine, Cambridge, 1969, British Congress of the History of Medicine, Cambridge, 1969,
ed. Arthur Rook. London, Wellcome Institute of the History of

3 Lancet, 1968, 2, 288.

Next week the B.M.f. will start publishing the Birmingham series of lectures under the heading "Scientific Basis of Clinical Practice."

\section{Any Questions?}

We publish below a selection of questions and answers of general interest

\section{Chemical Changes in Cooking Oils}

What chemical changes occur in vegetable oil, for example, corn oil, as a result of its use in deep or shallow frying. Are changes limited to temperatures beyond the "breaking" or "smoking" point? Have carcinogens been identified in the used oil?

There is no evidence that vegetable oil used for normal frying can be harmful. Chemical changes, mainly oxidation and polymerization, occur well below the smoke point but these affect mainly the physical properties of the oil and are more readily observed in commercial than in domestic frying. It seems that the products of these changes are either readily metabolized or are not absorbed at all, They do not resemble the types of compounds which have been found to cause cancer.

1 Artman, N. R., Advances in Lipid Research, 1969, 7, 245.

2 Lang, K., van Jan E. H., and Henschel, J., Zeitschrift für Errährungswissenschaft, 1969,'9, 363.

\section{Tinea Cruris}

What is the treatment for tinea cruris?

The causative fungi in tinea cruris are usually Epidermophyton floccosum, Trichophyton rubrum, or Trichophyton mentagrophytes. These dermatophytes are sensitive to oral griseofulvin, which should be given for 3-4 weeks. As a local application Whitfield's ointment is effective but Tinaderm (tolnaftate) or Variotin (pecilocin) ointment are usually more acceptable. Candida infection is occasionally mistaken for tinea cruris; it will respond to topical nystatin.

\section{Notes and Comments}

Toxicity of Tricyclic Drugs.-Dr. J. A. G. WATt (Royal Dundee Liff Hospital, By Dundee) writes: In response to a query about the toxicity of tricyclic antidepressant drugs given on a long-term basis ("Any Questions?" 31 July, p. 300) no mention is made of the reports of their cardiotoxic properties. These reports were admirably summed up in a recent leader. ${ }^{1}$

OUR EXPERT replies: This leading article referred mainly to the occasional sudden deaths associated with long-term phenothiazine treatment, which may result in quinidine-like effects on the heart. The best documented cases had all received 1-3 $\mathrm{g}$ of chlorpromazine or thioridazine daily. The only patient in the references who was on tricyclic antidepressants (without phenothiazines) had an atrial fibrillation and was eventually continued on his antidepressant medication. Tachycardia and occasional cardiac irregularities are early side effects of tricyclic antidepressants, and in their world review of the literature Meyler and Herxheimer ${ }^{2}$ considered them to be due to the anticholinergic effects. E.C.G. changes have also been recorded early in the treatment in up to $20 \%$ of patients. It is uncertain whether these represent an anticholinergic effect or indeed are harmless. ${ }^{3}$ However, if a patient is suffering from an acute cardiac disorder tricyclic antidepressants may be contraindicated. 4

\footnotetext{
1 British Medical fournal, 1971, 1, 3.

2 Meyler, L., and Herxheimer, A., Side Effects of Drugs, Amsterdam, Excerpta Medica Foundation, Vol. 6, 1968.

3 Schou, M., Acta Psychiatrica et Neurologica Scandinavica, 1963, 39, Suppl. 169.

4 Coull, D. C., Crooks, J., Dingwall-Fordyce, I., Scott, A. M., and Weir, R. D., Lancet, 1970, 2, 590.
} 